\title{
High-Temperature Ceramic Material with the Increased Erosive Firmness
}

ISSN: 2576-8840

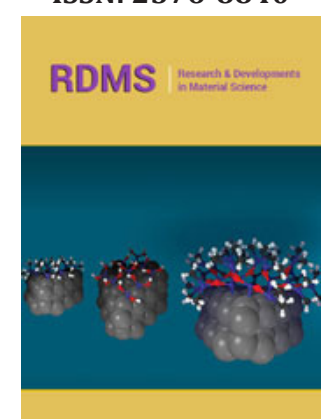

*Corresponding author: Kharitonov DV, JSC «ORPE «Technologiya» named after A. G. Romashin (Russia, Obninsk)

Submission: 海 May 17, 2019

Published: 㘹 May 22, 2019

Volume 11 - Issue 1

How to cite this article: Kharitonov $D$, Anashkina A, Kulikova G, Sher N, Baranov S. High-Temperature Ceramic Material with the Increased Erosive Firmness. Res Dev Material Sci. 11(1).RDMS.000751.2019. DOI: 10.31031/RDMS.2019.11.000751

Copyright@ Kharitonov DV, This article is distributed under the terms of the Creative Commons Attribution 4.0 International License, which permits unrestricted use and redistribution provided that the original author and source are credited.

\author{
Kharitonov DV*, Anashkina AA, Kulikova GI, Sher NE and Baranov SV \\ JSC «ORPE «Technologiya» named after A. G. Romashin (Russia, Obninsk)
}

Opinion

Increase in operating temperatures of the gas turbine engine hot path demands application of more high-temperature materials for the GTE metal elements production. In turn, it dictates more strict requirements to the refractory crucibles used in installations of vacuum induction melting of nickel alloys. Nowadays the greatest distribution was gained by the crucibles of mullite-corundum and corundum-zirconiumoxide-silicate structures differing in high thermal stability due to formation of microcracking structure. However, the presence of silicon at the ceramic structure leads to the increased erosion of refractory material and the pollution of metal by silicon. The most inert in relation to fusions of nickel are refractory materials of purely corundum structure with low open porosity.

The purpose of work is development of heat-resistant refractory material technology and formation technology of melting and security crucibles efficient to $1700{ }^{\circ} \mathrm{C}$, maintaining many heat changes and having the increased erosive firmness in relation to fusions of nickel and its alloys. The main requirements to products which are used in the conditions of sharp temperature drops taking place when melting metals are the high thermal stability and mechanical durability of material. The highest thermal stability is observed at ceramics with a coarse-grained filler. The choice of the materials suitable for operation at temperatures up to $1700^{\circ} \mathrm{C}$ is limited. Perspective and available option for the solution of the objective is material from coarse-grained corundum and mullite on corundum binding powders.

In the current work electrofusion mullite of fractions from 1 to $5 \mathrm{~mm}$ and electrocorundum of granularity F36 and F100 were used as the coarse-grained filler. The ratio of mullite and electrocorundum fractions was selected, proceeding from the maximum bulk density of the filler. The corundum slip prepared on technology of discrete wet grinding was used as binding. For obtaining the slip electrofusion corundum of granularity F36, phosphoric acid, distilled water and corundum spheres with a diameter 40 and (20-25) mm were used. The amount of the entered phosphoric acid made $0.2 \%$, and the general time of grinding - (10-12) hours.

After grinding the slip was obtained with density $(2.83-2.87) \mathrm{g} / \mathrm{cm}^{3}$ and $\mathrm{pH}(10.50-10.90)$. The sieve residue 005 made less than $2 \%$. The particle size distribution was determined by the laser analyzer of particles "Horiba" (Figure 1). The particle size distribution of the slip is presented by two fractions: particle size (9-11) micrometeres in the amount of $(72-75) \%$ and (1-2) micrometers in the amount of (20-23)\%; particle size (0.5-0.9) micrometeres takes place in a small amount (to $5 \%$ ).

Mixing of the filler and the slip was carried out in the centrifugal mixer within (5-7) minutes. Formation of products was carried out by vibrocasting method in plaster molds. The mechanism of fastening the molds on a vibrotable provided only axial vibrations for minimization of their horizontal components. For products of height (300-350) $\mathrm{mm}$ and diameter about $200 \mathrm{~mm}$ the optimum mode of vibrations was picked up. At humidity of molding weight (5.2-5.5) \% and the maintenance of the filler $60 \%$ of mass the time of curing of weight in mold makes (0.5-0.7) hours owing to change of coagulative structure on condensation.

Calcination of green preforms was carried out in the gas furnace of periodic action at temperature (1480-1500) ${ }^{\circ} \mathrm{C}$ and at the isothermal endurance from 8 to 10 hours. 


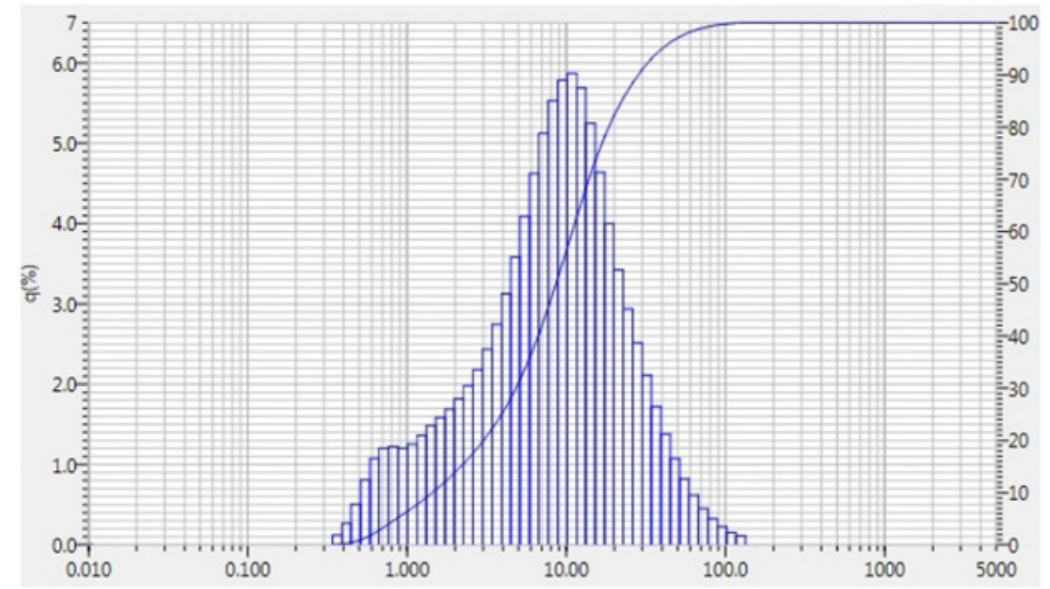

Figure 1: Particle size distribution of the slip.

The analysis of microstructure showed uniform distribution of the filler grains, pores and binding in the sintered product (Figure 2). The obtained crucibles have the average density of $3.1 \mathrm{~g} / \mathrm{cm}^{3}$ and open porosity of (14.0-14.2) \%. The resource of products when melting nickel alloys with the fusion overheat to $1700^{\circ} \mathrm{C}$ makes 23 25 fusions, at the same time the erosion of refractory material and pollution of fusion are not noted.

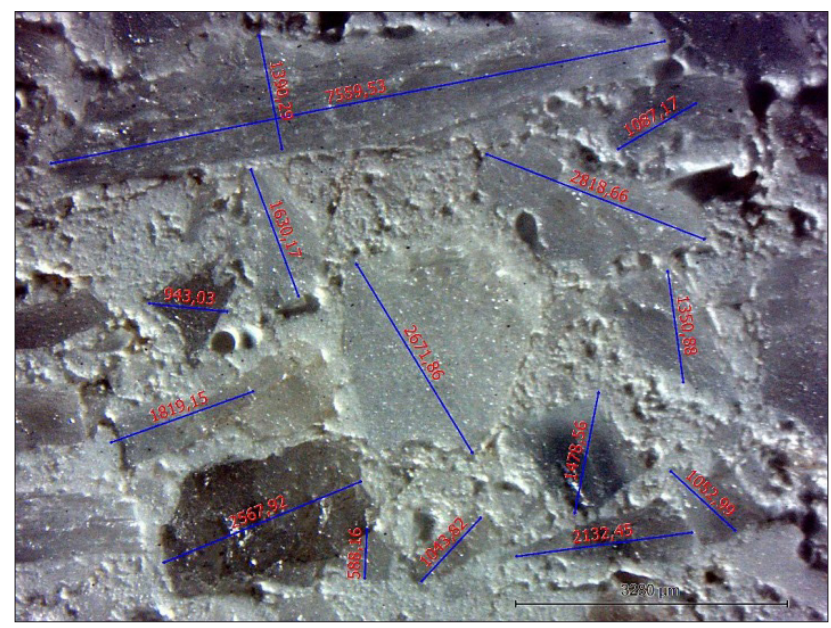

Figure 2: Microstructure of the material. 